\title{
Local community involvement in conservation - the use of mini-guides in a programme for sea turtles in Brazil
}

\author{
Claudia F. Vieitas, Gustave G. Lopez and Maria A. Marcovaldi
}

\begin{abstract}
The Brazilian Sea Turtle Conservation Programme (TAMAR) was established in 1980 to protect sea turtles in Brazil and to re-establish their natural life cycle, which had been disrupted by humans. The programme is based on grassroots involvement by the coastal communities, and provides jobs and generates alternative sources of income. Within this framework, the mini-guides programme was created. It consists of a summer training course in which local children between 8 and 13 years old learn basic information about marine ecosystems and sea turtles, strategies to promote their conservation, and skills to interact effectively with tourists. After the course, children are given onsite experience by working as interns at the TAMAR visitor centre at Praia do Forte, on schedules designed
\end{abstract}

to avoid conflicts with their studies at school. The children work closely with tourists, informing them about sea turtles and TAMAR's work; they also help the biologists in field activities. In this way, they enhance their own awareness, and by extension their families' and the community's concern about environmental conservation. Their involvement provides them not only with valuable skills, but also an extra source of income, thereby providing economic benefits to their families. The success of this programme is indicated by the excellent approval ratings given by the tourists visiting the area.

Keywords Children, community-based conservation, ecotourism, environmental education, marine turtles.

\section{Introduction}

Conservation projects are seldom successful without the involvement of local people, especially where the native population has been a strong force in the depletion of the resources (McNeely et al:; 1990; IUCN/SSC Marine Turtle Specialist Group, 1995; Durbin et al., 1996). Local people can also be an invaluable source of information in identifying threats. The continued success of conservation measures is often ensured when the rural population shares its benefits, be they social, environmental or economic. Tourism, for instance, can be a viable economic alternative for local people and a sustainable way of protecting natural resources (Boo, 1990).

Today, the implementation of successful conservation projects often includes environmental education and involvement of local communities. For sea-turtle recov-

Claudia F. Vieitas (corresponding author) rua Jacupiranga 57 , São Paulo-SP, 01440-050, Brazil. E-mail: cvieitas@originet.com.br

Gustave G. Lopez and Maria A. Marcovaldi Fundação Pró-TAMAR, Caixa Postal 2219, Salvador-BA, 40210-970, Brazil. E-mail: protamar@e-net.com.br

Received 22 April 1998. Accepted 21 September 1998 ery and management strategies the IUCN/SSC Marine Turtle Specialist Group (1995) encourages the active participation of coastal communities and the promotion of economic alternatives to the exploitation of sea turtles. Recent approaches also note that the partnership between government and non-governmental organizations (NGOs), in addition to local collaboration, helps to improve the implementation and long-term success of conservation initiatives (McNeely et al., 1990).

This paper describes the experience of local participation in wildlife conservation in the Brazilian Sea Turtle Conservation Programme (TAMAR), which involves children from the community of Praia do Forte, in Bahia state.

\section{Site description and historical background}

All seven species of sea turtles in the world are currently threatened with extinction (IUCN, 1996). In order to prevent their disappearance from Brazil, in 1980 the federal government, through IBAMA (Brazilian Agency for Environment), created the Brazilian Sea Turtle Conservation Programme (TAMAR; an acronym for sea turtle in Portuguese, TArtaruga MARinha). In order to promote marine conservation and help the TAMAR Programme, the Pró-TAMAR Foundation was created in 1988. It is a non-profit organization responsible for 


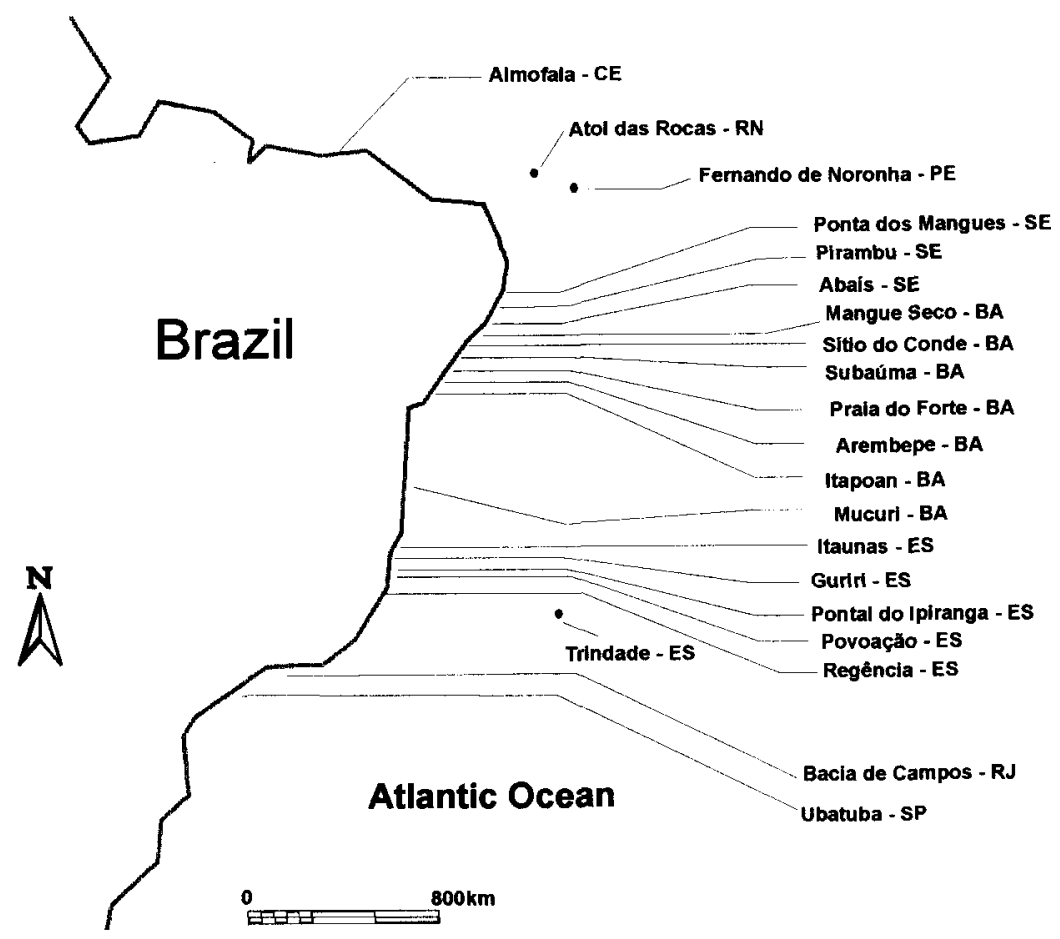

Fig. 1 TAMAR stations in Brazil.

managing more than 60 per cent of TAMAR's operations and paying the salaries of about 90 per cent of approximately 400 employees, most of them from local communities, involved in the daily activities of sea turtle conservation.

The programme works to protect principal nesting beaches and feeding grounds of turtles in Brazil as a means of re-establishing their natural life cycle that has been disrupted by people. The success of TAMAR is based on grassroots involvement with the coastal communities. Besides providing paid work, directly and indirectly, it looks for creative ways of generating alternative sources of income for the villagers. The employment of former egg poachers to protect turtle eggs, and the continual environmental education work has led to a change in behaviour in these communities.

TAMAR currently operates 21 stations along the coast of Brazil. The stations are staffed year-round and promote not only the conservation of sea turtles, but also organize cultural festivals, support healthcare facilities, schools and other community activities. The headquarters are located in Praia do Forte, Bahia, on the north-east coast, $70 \mathrm{~km}$ from Salvador (Fig. 1). Its visitor centre receives more tourists than any other TAMAR station.

TAMAR started in Praia do Forte in 1982, when it was a village of 600 inhabitants. The main sources of income were fishing and a nearby coconut plantation. Soon after TAMAR established a base there, tourists began to visit, either for the day or for extended stays at the resort. More tourism development ensued, and today tourism is the main source of income in Praia do Forte, with about 2500 people visiting the beach every day in summer.

The TAMAR station has a visitor centre that is open daily from 09.00 to 18.00 hours. It has an open-air beach hatchery and five display tanks (the smallest being $2.7 \mathrm{~m}$ and the largest $5.7 \mathrm{~m}$ in diameter) holding about 20 sea turtles of different ages and species, for environmental education purposes. There are also four shops that sell TAMAR products made by residents of the coastal communities, a small museum with a video cassette recorder, a computer with multimedia programmes, turtles shells and skeletons, and a snack bar.

\section{Turtles and tourism}

The sea-turtle nesting populations and management activities of TAMAR, at Praia do Forte, have been described by Marcovaldi \& Laurent (1996). The villagers now rely on sea turtles as a living resource because they are a major tourist attraction and generate income, so they help protect their nests and beaches. Turtle nests remain on their original sites and are marked with stakes. People respect the stakes and do not interfere with the nests. Turtles generally nest at night, when there are usually no tourists on the beach, but occasionally an encounter with a nesting turtle 
Plate 1 Mini-guides course. Through theatre presentations with a turtle character, the children taking the course learn about biology and conservation of sea turtles.

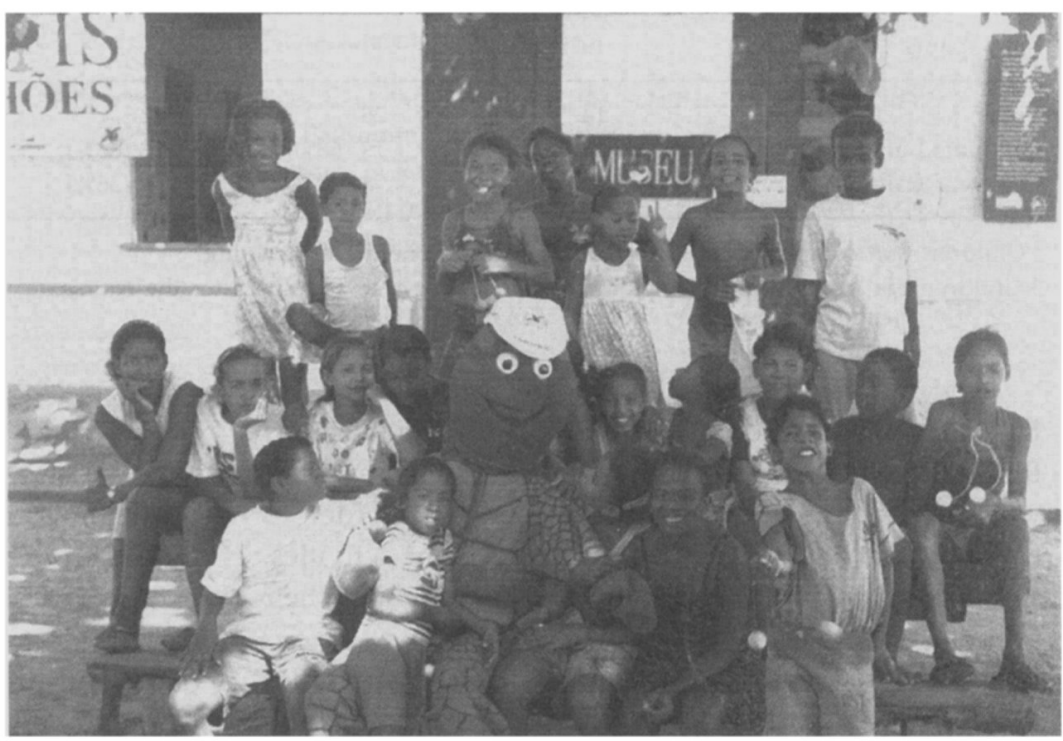

might occur. There are, so far, no records of turtles being disturbed in this way. Despite the fact that the beach is $14 \mathrm{~km}$ long, most tourists remain within a 2-km stretch, near the village. Resorts and houses have been constructed in such a way as to minimize their impact on turtles; for instance, beachfront illumination has been minimized and nearby lights have been screened, as recently recommended by Witherington \& Martin (1996). In effect, there is little conflict between the needs of the turtles and the needs of the tourists.

TAMAR is increasing awareness of sea turtles by various means. Two examples of this at Praia do Forte are the mini-guides programme and the turtle by night programme (Vieitas \& Marcovaldi, 1997). The first is part of TAMAR's strategy to involve local people in conservation as well as to provide training and professional experience to the children. The second is an ecotourism initiative, to raise awareness among tourists about sea turtle conservation.

\section{The mini-guides programme}

The mini-guides programme is based on a short summer course for local children that provides training skills needed to guide tourists, as well as conservation information Each summer 8-13-year-old children spend 2 weeks learning basic information on the topics listed below:

1 Sea turtles: life cycle, identification of species, general behaviour, feeding habits and basic care at the TAMAR station.

2 Conservation: main threats facing sea turtles, TAMAR's management and conservation techniques for all life stages of the turtles, basic procedures for protecting sea turtles, TAMAR's community-based conservation work, importance of habitat and marine conservation.

3 Tourist-guide procedures: behaviour with tourists, speech and ways of interacting with visitors.

These topics are covered mainly through field trips to the beach, reefs, turtle nests and other major tourist attractions in the region. They also learn through practical experiences: opening nests in which turtles have hatched to count and identify unhatched eggs and embryos, releasing hatchlings and feeding turtles in display tanks. Additional learning is provided by video exhibits, theatre presentations, puzzles, and informal activities such as picnics and parties (Plate 1). A handbook on marine conservation and turtle biology is an additional educational resource.

After the course, groups of six children work at the TAMAR visitor centre to complete their training. During this period, each child receives a stipend. The children inform tourists about sea turtles and TAMAR's work. They also have the opportunity to watch and help the biologists in field activities and to participate in the turtle by night programme (Vieitas \& Marcovaldi, 1997). After this training, the guides who demonstrate the best communication skills, behaviour in the visitor centre, and knowledge of sea turtles and TAMAR's work are invited to remain working at the visitor centre throughout the year.

In order to avoid overlap with school, each child works only during the weekends or part-time during weekdays. The children are taught how to structure their own daily activities, as well as the work for TAMAR. They undertake various tasks: responding to 


\begin{tabular}{lcccc}
\hline Participants & $1995 / 96$ & $1996 / 97$ & $1997 / 98$ & Total \\
\hline Total & 14 & 28 & 22 & 64 \\
Graduated after training* & $6(43 \%)$ & $19(68 \%)$ & $19(86 \%)$ & $44(69 \%)$ \\
One-year trainingt & $4(29 \%)$ & $8(29 \%)$ & $8(36 \%)$ & $20(31 \%)$ \\
\hline
\end{tabular}

Table 1 Number of children participating in the mini-guides programme per season

* Children that completed the short course and the one-month training.

+ Children that completed all steps including the one-year training after the course.

letters, using the Xerox machine, organizing days off for themselves, co-ordinating lunch-time breaks at weekends and working in the museum. In order to enable each child to experience the different activities, they take turns and help each other by teaching their previous tasks.

The one-year experience enables the mini-guides from one year to help in programming and teaching the following year's course. In addition, one or two children from each year stay for some months to help the new guides adapt.

As well as training children in tourist guiding activities, the programme also aims to achieve the objectives listed below.

- Involve the coastal community in conservation projects and in ecotourism activities.

- Give children an opportunity to work with conservation and ecotourism projects in the area, helping to raise environmental awareness among tourists.

- Enhance local community concern about environmental conservation through the children.

- Create new opportunities and sources of income for the children involved, without jeopardizing their regular study at school, thus helping not only them but also their families.

\section{Results and discussion}

After a pilot project in the 1995/96 turtle nesting season, full mini-guides courses were given in the 1996 / 97 and 1997/98 seasons (Table 1).

The main activity of the children was to guide and inform tourists in the museum as well as at the display tanks and open-air egg hatcheries. The children gained valuable experience in operating computers and audio-visual equipment, which they might not have had otherwise. Mini-guides also passed on these skills to their friends, who often came to the visitor centre.

After the course and for the rest of the turtle nesting season, most of the children came daily to the beach hatcheries at sunset, when nests from which hatchlings had emerged were opened. They participated, with the biologists, in identifying hatchling species, counting embryos and egg shells, and informing tourists about these procedures, improving their own knowledge on sea turtles, management techniques and communication skills.

Each year after the pilot year, when only four children underwent the one-year training, following the one-month training internship, eight children were selected to work at TAMAR's visitor centre for the rest of the year. Four worked during weekends and four on weekdays, two in the morning and two in the afternoon. This schedule was devised to avoid conflicts with school.

The mini-guides were monitored daily and given brief training sessions to keep them prepared to meet the needs of tourists. Despite their young age, the mini-guides were entrusted with some responsibilities, usually specific for each guide, to bolster confidence and self-esteem. They often showed initiative and creativity; for example, they organized a 'fishing game' stall for a village street festival, being responsible for all the organization, from ticket sales to distribution of prizes.

After 6-months' training, we recognized the need to integrate further the mini-guides in the day-to-day activities of TAMAR. A first step was to teach the miniguides to answer children's letters requiring information on turtles. We taught basic computer skills and explained what should be included in the replies. These practices stimulated and improved writing and learning the Portuguese language, and so far have had very good results, both for the children and for TAMAR.

Between July 1997 and February 1998, tourists visiting the TAMAR station were asked about several aspects of the visitors' centre, such as the museum facilities, turtle display tanks, informative signs, video presentation and mini-guides. Their answers showed that mini-guides were a very positive aspect of TAMAR's visitor centre: more than 80 per cent of 2040 interviewees considered the mini-guides activities good or very good (Table 2).

The positive outcomes of this programme were much greater than were anticipated at the outset, resulting in greater involvement of the community in 
Table 2 Evaluation of the mini-guides activities by tourists at TAMAR visitor's centre

\begin{tabular}{ll}
\hline Evaluation & Percentage of votes \\
\hline Very good & 58.04 \\
Good & 22.24 \\
Average & 10.00 \\
Poor & 9.72 \\
\hline
\end{tabular}

conservation activities, a strong emphasis on teamwork and co-operation, and imparting skills to the children for the future.

\section{Conclusions}

Our aim for this programme was to motivate children to participate in conservation and involve them in raising environmental awareness among tourists. We hope that by involving them in such activities they might use this experience on their own behalf, perhaps by applying their new skills in a job elsewhere, and to spread their enthusiasm to their family members, thereby enhancing community concern about the environment. The process of involving children in management can be seen as a benefit for all concerned: the biologists are training people that can assist in fieldwork in the future, and the children are gaining experience in an important skill for the area. The involvement of local people in conservation of natural resources is becoming a necessary and increasingly common practice because most of Earth's biodiversity now lies in non-protected areas inhabited by human beings (Western \& Wright 1994). In this way, communitybased conservation and involvement of villagers in programmes such as this can serve as a model for a sustainable living and coexistence with the natural world.

\section{Acknowledgements}

We thank Charles Tambiah and Matthew Godfrey for reviewing the manuscript. This programme was made possible by the participation of TAMAR staff and interns, who helped train the children. Fundo Nacional do Meio Ambiente (FNMA/MMA) sponsored a pilot project of the mini-guides programme. TAMAR is affiliated with IBAMA, comanaged by Fundação PróTAMAR and officially supported by PETROBRAS.

\section{References}

Boo, E. (1990) Ecotourism: the Potentials and Pitfalls. WWF, Baltimore.

Durbin, J., Rajafetra, V., Reid, D. \& Razandrizanakanirina, D. (1996) Local people and Project Angonoka-conservation of the ploughshare tortoise in north-western Madagascar. Oryx, 30(2), 113-120.

IUCN (1996) 1996 IUCN Red List of Threatened Animals. IUCN, Gland, Switzerland.

IUCN/SSC Marine Turtle Specialist Group (1995) A Global Strategy for the Conseroation of Sea Turtles. IUCN, Gland, Switzerland.

Marcovaldi, M.A. \& Laurent, A. (1996) A six season study of sea turtles nesting at Praia do Forte, Bahia, Brazil, with implications for conservation and management. Chelonian Conservation and Biology, 2(1), 55-59.

McNeely, J.A., Miller, K.R., Reid, W.V., Mittermeier, R.A. \& Werner, T.B. (1990) Conserving the World's Biological Diversity. IUCN, Gland, Switzerland.

Vieitas, C.F. \& Marcovaldi, M.A. (1997) An ecotourism initiative to increase awareness and protect sea turtles in Brazil: the turtle by night program. Chelonian Conservation and Biology, 2(4), 607-610.

Western, D. \& Wright, R.M. (1994) The background to community based conservation. In Natural Connections: Perspectioes in Community-based Conservation (eds D. Western and R. M. Wright), pp. 1-12. Island Press, Washington, DC.

Witherington, B.E. \& Martin, R.E. (1996) Understanding, assessing and resolving light-pollution problems on sea turtle nesting beaches. Florida Marine Research Institute Technical Reports TR-2, pp. 1-73.

\section{Biosketches}

Claudia $F$. Vieitas received her graduate degree in environmental sciences working with conservation of coastal islands in south-eastern Brazil. She maintains an interest in management of native populations and their habitat, as well as protected areas. She is also interested in the overlap between conservation of natural resources and environmental education, and is involved with ecotourism and public awareness of environmental issues.

Gustave G. Lopez has participated in research projects involving animal ecology and marine conservation. He also has a keen interest in community outreach programmes, conservation of biological diversity, as well as restoration and landscape ecology.

Neca Marcovaldi was trained as an oceanographer before helping to found Projeto TAMAR, the Brazilian Sea Turtle Conservation Programme, in 1980. Besides continuing to work within Projeto TAMAR, she is also the president of an NGO dedicated to supporting turtle conservation. She has served on the executive committee of the SSC/IUCN Marine Turtle Specialist Group since 1993, and is the representative for Brazil in WIDECAST (Wider Caribbean Conservation Network). 